\title{
Experimental Investigations on Adsorption of Reactive Toxic Dyes Using Hedyotis umbellate Activated Carbon
}

\author{
Jayachandran Sheeja ${ }^{(D},{ }^{1}$ Krishnan Sampath, ${ }^{2}$ and Ramasamy Kesavasamy ${ }^{3}$ \\ ${ }^{1}$ Department of Chemistry, Sri Ramakrishna Engineering College, Coimbatore 641022, India \\ ${ }^{2}$ Department of Chemistry, Kumaraguru College of Technology, Coimbatore 641049, India \\ ${ }^{3}$ Department of Physics, Sri Ramakrishna Engineering College, Coimbatore 641022, India
}

Correspondence should be addressed to Jayachandran Sheeja; sheeja.jayachandran@srec.ac.in

Received 12 October 2019; Accepted 17 July 2021; Published 30 August 2021

Academic Editor: Tushar Sen

Copyright (C) 2021 Jayachandran Sheeja et al. This is an open access article distributed under the Creative Commons Attribution License, which permits unrestricted use, distribution, and reproduction in any medium, provided the original work is properly cited.

\begin{abstract}
Hedyotis umbellate activated carbon (HUAC) was prepared by chemical and thermal activation. The adsorption behavior of Hedyotis umbellate activated carbon in aqueous basic green 4 (BG4) and acid fuchsin (AF) was investigated and characterized by UV-vis, FTIR, and FESEM. The possible mechanism of the adsorption of BG4 and AF dyes on the HUAC surface was framed. The influence of various adsorption control parameters like the initial dye concentration, $\mathrm{pH}$, adsorbent dose, contact time, and temperature was studied. The data confirmed excellent BG4 removal of $97.94 \%$ at $\mathrm{pH} 10$ and AF removal of $76.7 \%$ at pH 4. The experimental data were fitted using Langmuir, Freundlich, and Temkin isotherms to examine the adsorption mechanism. The adsorption data revealed monolayer adsorption of BG4 with the maximum capacity of $102.38 \mathrm{mg} / \mathrm{g}$ and multilayer adsorption of AF with the capacity of $139.33 \mathrm{mg} / \mathrm{g}$. The kinetic data for different initial dye concentrations were computed using pseudofirst order, pseudosecond order, and intraparticle diffusion models. Thermodynamic parameters like Gibbs free energy change $\Delta G^{0}$, enthalpy change $\Delta H^{0}$, and entropy change $\Delta S^{0}$ were evaluated. From the values obtained, the negative values of $\Delta G^{0}$ and $\Delta H^{0}$ indicate that the adsorption of BG4 and AF by HUAC is spontaneous and exothermic.
\end{abstract}

\section{Introduction}

The wastewater generated from industries contains heavy loads of colored effluents that are highly ecotoxic to aquatic organisms due to synthetic dyes and coloring pigments. Synthetic dyes are used in textiles, paper, printing, plastics, tanneries, cosmetics, pharmaceuticals, food, color photography, and petroleum. These dyes have a stable, symmetric, and complex aromatic structure that make them nondegradable. Their presence causes adverse impacts to aquatic environment. Basic green 4 is a direct dye used for silk, cotton, wool, jute, leather, and paper and in aquaculture as a parasiticide. However, the consumption of the dye causes carcinogenesis, mutagenesis, and chromosomal fractures [1]. Acid fuchsin or acid violet 19 is used for staining procedures, as a corrosion inhibiting substance for copper, in organic-inorganic hybrid nanocomposites preparation, and as a laboratory reagent. It is also used in selective inhibition of human immunodeficiency virus type 1 (HIV-1) and type 2 (HIV-2) in vitro [2]. Exposure of skin to acid fuchsin causes redness and itching, ingestion causes irritation and burning sensations of mouth and throat, nausea, vomiting, and abdominal pain, and inhalation causes irritation of mucous membranes, coughing, wheezing, and shortness of breath [3].

Though many conventional techniques are reported for wastewater treatment such as coagulation, precipitation, sedimentation, filtration, and color irradiation, the technical and economical disadvantages have resulted in using biosorption method that has been found to be efficient and cost-effective. The use of activated biosorbent not only serves to control pollution but also reduces agricultural waste generation. Various agricultural waste biomaterials were used for biosorption process such as rambutan seed [4], spent tea leaves [5], carob [6], Elaeagnus stone [7], pomelo peels [8], rice husk [9], sugar beet pulp [10], and malted sorghum mash 


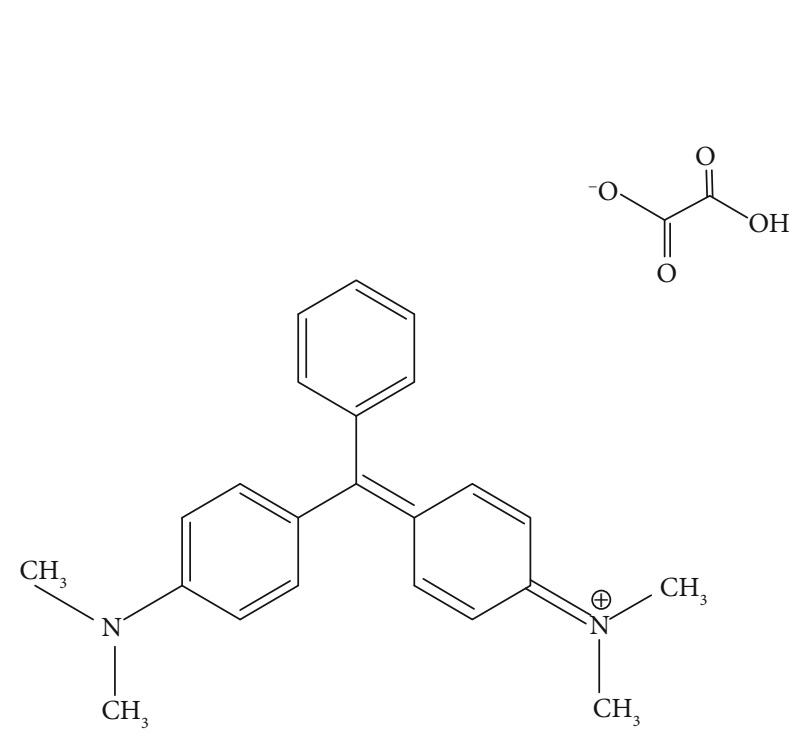

(a)

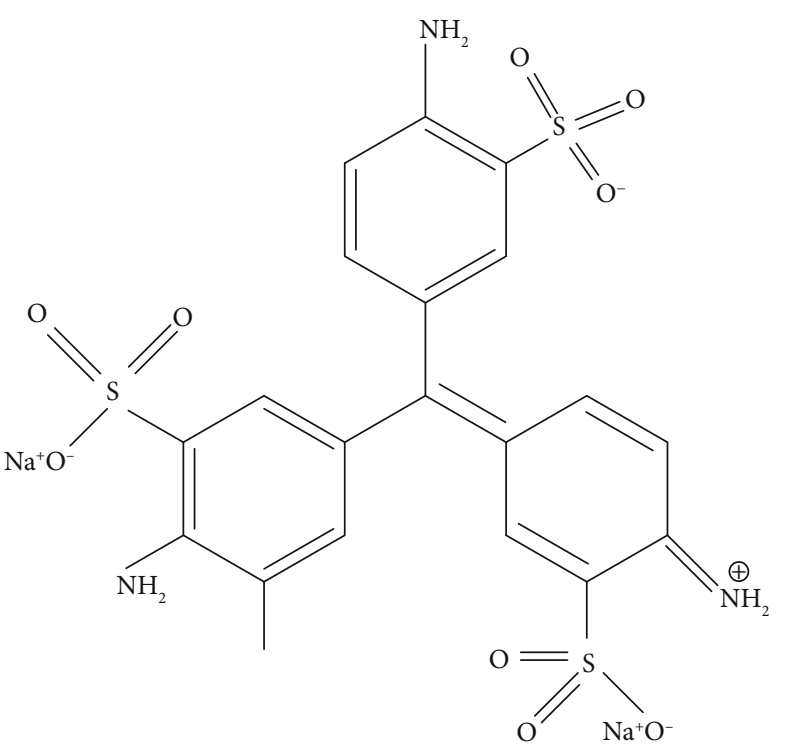

(b)

Figure 1: Molecular structure of (a) basic green 4 dye and (b) acid fuchsin.

[11]. The remarkable adsorption characteristics of activated carbon are that it contains small, low-volume pores that increase the surface area available for adsorption or chemical reactions. Hedyotis umbellate (Rubiaceae family), also known as Oldenlandia umbellate, is a low-growing tree native to India. Its leaves are used for the treatment of asthma, bronchitis, and catarrhal bronchitis [12], whereas its bark is abandoned as agricultural waste. In the present work, Hedyotis umbellate bark is rich in glycosides, and cheap and abundantly available agricultural waste is chemically activated and used to carry out adsorption of aqueous basic green 4 (BG4) and acid fuchsin (AF). The isotherm, kinetic, and thermodynamic analyses were done to determine the feasibility of using this material as a cost-effective and efficient adsorbent.

\section{Materials and Methods}

2.1. Preparation of Adsorbent and Adsorbate. The dried bark of Hedyotis umbellate was subjected to chemical activation with $50 \%$ by volume of sulphuric acid on constant stirring for 12 hours at room temperature [13]. The charred product was separated from the acid and soaked in 10\% sodium bicarbonate to remove the residual acid from its pores. It is then heated in a vacuum at $500^{\circ} \mathrm{C}$ for 2 hours and cooled, crushed, and sieved using 75-micron sieve. Basic green 4 (C.I - 42000) and acid fuchsin were purchased from Loba Chemie Ltd. India and used to prepare adsorbate solutions. The stock solution of the dyes of $1000 \mathrm{ppm}$ was prepared using double distilled water.

\section{Experimental}

A series of dye solutions were prepared by adjusting the $\mathrm{pH}$ over a range of 3-10 using $0.1 \mathrm{~N} \mathrm{HCl}$ and $0.1 \mathrm{~N} \mathrm{NaOH}$ solutions to evaluate the role of $\mathrm{pH}$ on adsorption of $\mathrm{BG} 4$ and $\mathrm{AF}$ dyes onto HUAC. The experiment was carried out using $50 \mathrm{ml}$ of the aqueous BG4 and AF dyes at concentrations varying between $10-100 \mathrm{mgL}^{-1}$. It was treated with $0.03 \mathrm{~g}$ of HUAC and shaken in bench top incubator cum orbital shaker at a constant speed of $100 \mathrm{rpm}$ for a time period of 75 mins. Residual dye concentration was recorded using a double beam UV/vis spectrophotometer (Model: Analytik/Jena, Germany) at $617 \mathrm{~nm}$ for BG4 and $543 \mathrm{~nm}$ for AF for which the molecular structure is shown in Figure 1.

The equilibrium amount of dye adsorbed on HUAC was calculated by equation 1, and the removal efficiency of the dye in percentage was calculated by equation 2 as listed in Table 1.

3.1. Adsorption Isotherms. The adsorbate-adsorbent interaction at equilibrium was found by fitting the experimental data in Langmuir, Freundlich, and Temkin equations 3, 4, and 5, respectively, as summarized in Table 1 .

3.2. Kinetic Studies. The equations 7,8 , and 9 shown in Table 1 were used to examine the reaction kinetics for a specific contact time, $t(30,60,75,90,120$, and $150 \mathrm{~min}$.) using $0.1 \mathrm{~g}$ and $0.03 \mathrm{~g}$ of HUAC with $50 \mathrm{ppm}$ BG4 and $100 \mathrm{ppm}$ $\mathrm{AF}$ dye solutions, respectively, at room temperature.

3.3. Thermodynamic Studies. The thermodynamic nature of adsorption of BG4 and AF onto HUAC was studied using Gibbs and Van't Hoff equations 10 and 11 as given in Table 1.

3.4. Characterization of HUAC. The physical characteristics of HUAC such as $\mathrm{pH}$, moisture content, ash content, bulk density, solubility in water, and acids were examined.

The $\mathrm{pH}$ of $1 \%$ adsorbent suspension was determined by standard test method. $1.0 \mathrm{~g}$ of HUAC was taken with $100 \mathrm{ml}$ of double-distilled water and stirred for $1 \mathrm{hr}$. The $\mathrm{pH}$ of the suspension was recorded using a $\mathrm{pH}$ meter. Initially weighed HUAC sample was heated in electric hot air 
TABLE 1: Equations of adsorption functions.

\begin{tabular}{lcc}
\hline Equation number & Adsorption function & Equation \\
\hline 1. & Equilibrium amount of dye adsorbed & $q_{e}=\left(C_{0}-C_{e} / M\right) \times V$ \\
2. & Removal efficiency, $\%$ & $\left(\left(C_{0}-C_{e}\right) /\left(C_{0}\right)\right) \times 100$
\end{tabular}

Where $C_{0}$ is the initial dye concentration, $C_{e}$ is the final dye concentration at equilibrium, $V$ is the operating volume of the solution, and $W$ is the mass of adsorbent.

Adsorption isotherms

3.

Langmuir isotherm

4.

Dimensionless separator factor

$1 / q_{e}=1 / q_{m}+1 / K_{L} C_{e} q_{m}$

$R_{L}=1 /\left(1+K_{L} \times C_{e}\right)$

5.

Freundlich isotherm

$\log q_{e}=\log K_{F}+(1 / n) \log C_{e}$

6.

Temkin isotherm

$q_{e}=(\mathrm{RT} / b) \ln \left(A_{T}+C_{e}\right)$

Where $q_{e}$ is the amount of dye adsorbed per $\mathrm{g}, q_{m}$ is the monolayer adsorption capacity, $K_{L}$ is Langmuir adsorption constant, $n$ is Freundlich constant, $K_{F}$ is Freundlich coefficient, $A_{T}$ is Temkin binding constant, and $b$ is Temkin isotherm constant. Kinetic studies

7.

Pseudofirst order equation

$\log \left(q_{e}-q_{t}\right)=\log q_{e}-k_{1} t / 2.303$

8.

Pseudosecond order equation

$t / q_{t}=\left(1 / k_{2} q_{e}^{2}\right)+t / q e$

Intraparticle diffusion

$q_{t}=k_{i} t^{1 / 2}+C$

Where $q_{e}$ is the amount of dye absorbed at equilibrium, $q_{t}$ is the amount of dye absorbed at any time $t, k_{1}$ is the pseudofirst order rate constant in $\mathrm{s}^{-1}, k_{2}$ is the pseudosecond order rate constant, $k_{i}$ is the intraparticle diffusion rate constant, and $C$ is the intercept.

Thermodynamic studies

10.

Gibbs equation

$\Delta G^{0}=-\mathrm{RT} \ln K_{L}$

11.

Van't Hoff equation

$\Delta G^{0}=\Delta H^{0}-T \Delta S^{0}$

Where $K_{L}$ is the equilibrium constant, $\Delta G^{0}$ is Gibbs free energy change, $\Delta H^{0}$ is change in enthalpy of adsorption, $\Delta S^{0}$ is entropy change, and $T$ is the operating temperature.

oven at $105-110^{\circ} \mathrm{C}$ for $1 \mathrm{hr}$ and cooled in dessicator. From the weight loss, the moisture content of HUAC was calculated. HUAC sample was heated to $750^{\circ} \mathrm{C}$ in a muffle furnace for 30 minutes, and the weight of ash formed was used to calculate the percentage of ash content. $1 \mathrm{~g}$ of HUAC was treated with $25 \mathrm{ml}$ of dilute hydrochloric acid and boiled for $5 \mathrm{~min}$. The filtrate was evaporated to dryness at $100-105^{\circ} \mathrm{C}$, and the solubility in acid was calculated.

FTIR analysis was carried out using the Bruker-ALPHA II model. FTIR spectrum of HUAC before and after the adsorption of BG4 and AF dye was obtained in the range of $4000-400 \mathrm{~cm}^{-1}$ and examined to confirm the adsorption of dyes by HUAC.

The surface morphology of HUAC was characterized by field emission scanning electron microscopy (FESEM) using the Zeiss Sigma model.

\section{Results and Discussion}

4.1. Characterization of the Adsorbent. From Table 2, the $\mathrm{pH}$ of HUAC shows that its surface is neutral to the reactivity of dyes. The low percentage of moisture and ash depicts the predominance of the percentage of carbon in HUAC for more adsorption. The lower value of bulk density indicates less compactness and more porous nature of HUAC. The solubility in water and acid values indicates its suitability with aqueous acid and basic dyes.
TABLE 2: Characteristics of activated carbon.

\begin{tabular}{lc}
\hline Parameters & Value \\
\hline pH 1\% solution & 6.24 \\
Moisture content (\%) & 4.35 \\
Ash content (\%) & 1.88 \\
Bulk density (g/ml) & 0.5663 \\
Solubility in water (\%) & 4.8 \\
Solubility in acid (\%) & 8.2 \\
\hline
\end{tabular}

From the FTIR spectra of HUAC, HUAC-BG4, and HUAC-AF as displayed in Figures 2(a)-2(c), respectively, it is observed that there is a peak shift in Figures 2(b) and 2(c) due to the presence of relative functional groups of BG4 and AF dyes indicating adsorption onto HUAC [14]. The FTIR spectrum of HUAC indicates peaks at 3747 and $2925 \mathrm{~cm}^{-1}$ that ascribe to hydrogen bridges [15] and -CHasymmetric stretching of $-\mathrm{CH}_{3}$ group, respectively. The peak between $1750-1600 \mathrm{~cm}^{-1}$ indicates $\mathrm{C}=\mathrm{O}$ stretching, two sharp peaks in the range of $1550-1500 \mathrm{~cm}^{-1}$ correspond to $-\mathrm{C}=\mathrm{C}-$ stretching, and a broadband at $1157 \mathrm{~cm}^{-1}$ corresponds to C$\mathrm{H}$ out-of-plane wagging [16]. The FTIR spectrum of HUAC-BG4 in Figure 2(b) shows sharp peaks between 3900 and $3600 \mathrm{~cm}^{-1}$ due to $\mathrm{O}-\mathrm{H}$ bonding $\left(\mathrm{H}_{2} \mathrm{O}\right)$. The peaks at 2983 and $2897 \mathrm{~cm}^{-1}$ are of $\mathrm{O}-\mathrm{H}$ stretching of carboxylic acid and $-\mathrm{C}-\mathrm{H}-$ stretching, respectively [17]. The bands located at $1523 \mathrm{~cm}^{-1}$ and $779 \mathrm{~cm}^{-1}$ attribute to $-\mathrm{N}-\mathrm{H}$ bending 


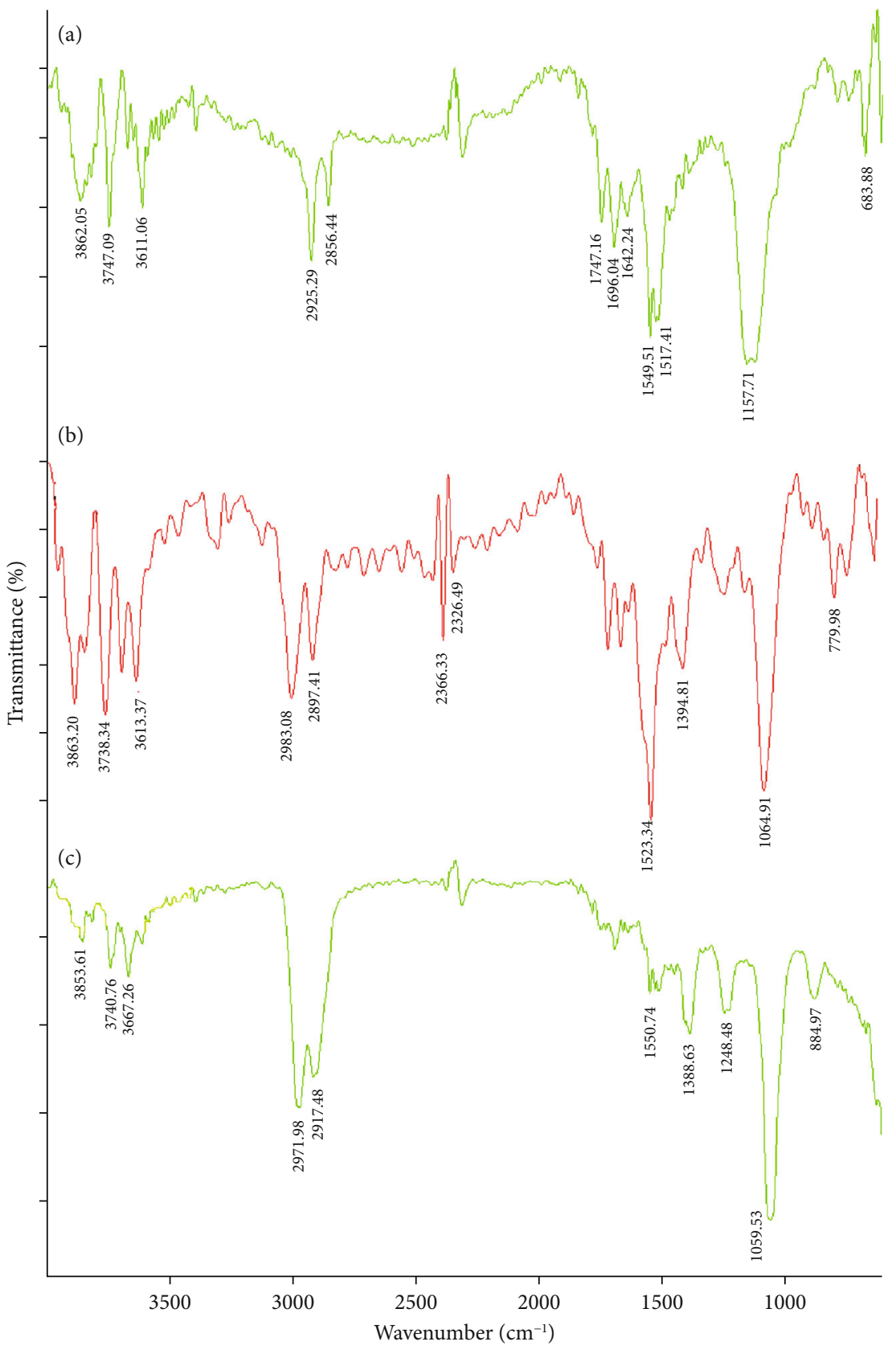

Figure 2: FT-IR spectrum of (a) HUAC, (b) HUAC-BG4, and (c) HUAC-AF.

and $-\mathrm{N}-\mathrm{H}$ rocking, respectively, and a sharp band at $1064 \mathrm{~cm}^{-1}$ confirmed the absorption of $\mathrm{C}-\mathrm{N}^{3}$ stretching. The FTIR spectrum of HUAC-AF in Figure 2(c) has medium peaks in the range $3800-3600 \mathrm{~cm}^{-1}$ that belongs to $\mathrm{O}-\mathrm{H}$ stretching. Two strong and sharp peaks at $2971 \mathrm{~cm}^{-1}$ and $1059 \mathrm{~cm}^{-1}$ are attributed by $-\mathrm{C}-\mathrm{H}$ aromatic stretching and sulfoxide groups of AF dye, respectively. Medium peaks at $1550 \mathrm{~cm}^{-1}$ and $1248 \mathrm{~cm}^{-1}$ correspond to $\mathrm{C}=\mathrm{N}[18]$ and $\mathrm{C}-\mathrm{N}$ stretching of aromatic primary amines, respectively.

The surface morphologies of HUAC, BG4 loaded HUAC, and AF loaded HUAC were investigated using FESEM micrographs. Figure 3(a) shows the FESEM photograph of sulphuric acid-activated HUAC that possess large pores with wide cavities needed for the adsorption purpose and amena- ble for the binding of relative functional groups of the dyes. Figure 3(b) represents the FESEM photograph of BG4 loaded HUAC that exhibits a rough surface in which the pores are closed with the dye deposits, and Figure 3(c) displays the FESEM photograph of AF loaded HUAC that shows the heterogeneous aggregation of the dye.

The UV-vis spectrum of BG4 and AF solutions before and after adsorption was recorded to have more information on the adsorption of both the dyes and is shown in Figures 4(i) and 4(ii), respectively. An intense absorption peak for BG4 is found at $615 \mathrm{~nm}$ in Figure 4(i) (a), and the intensity of the peak decreases quickly after maximum adsorption of the dye as seen in Figure 4(i) (b). The removal of AF dye from the solution is also clearly shown in 


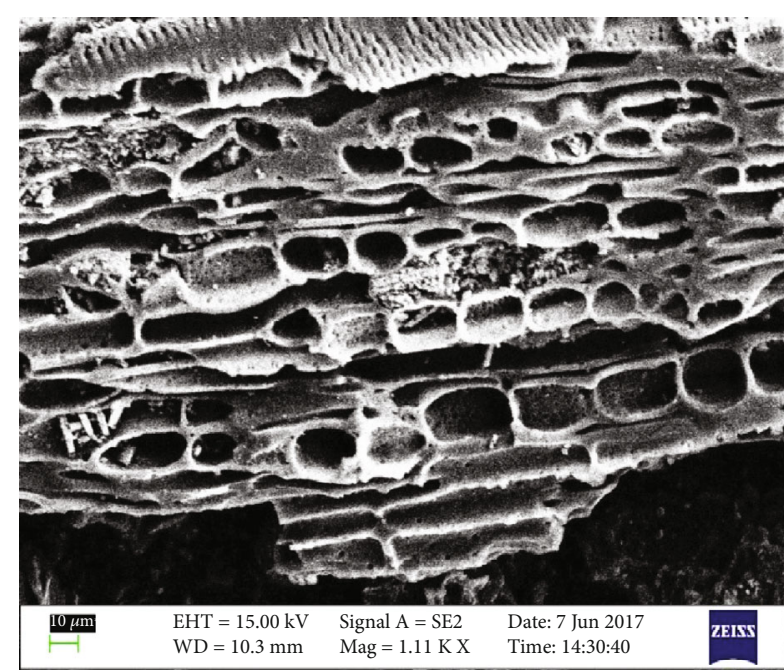

(a)

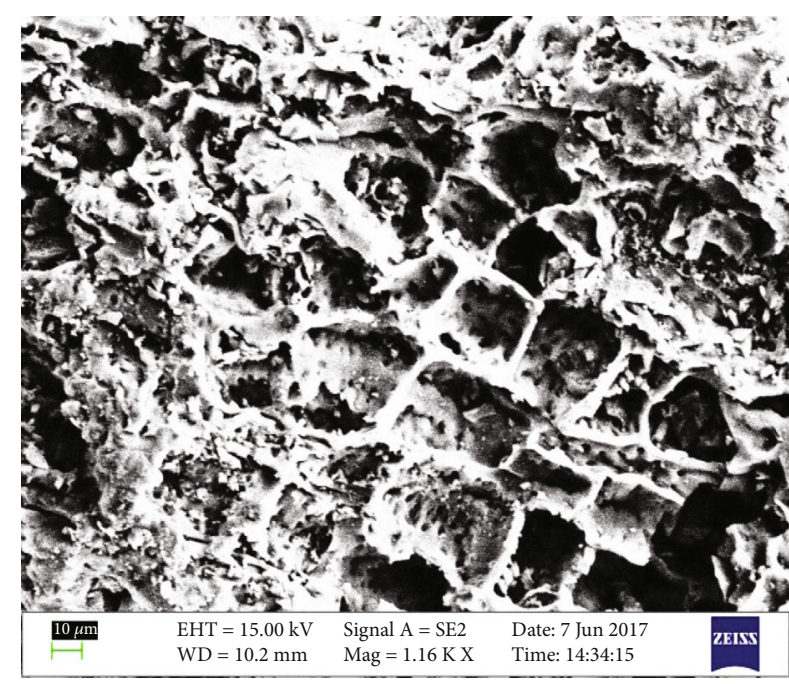

(b)

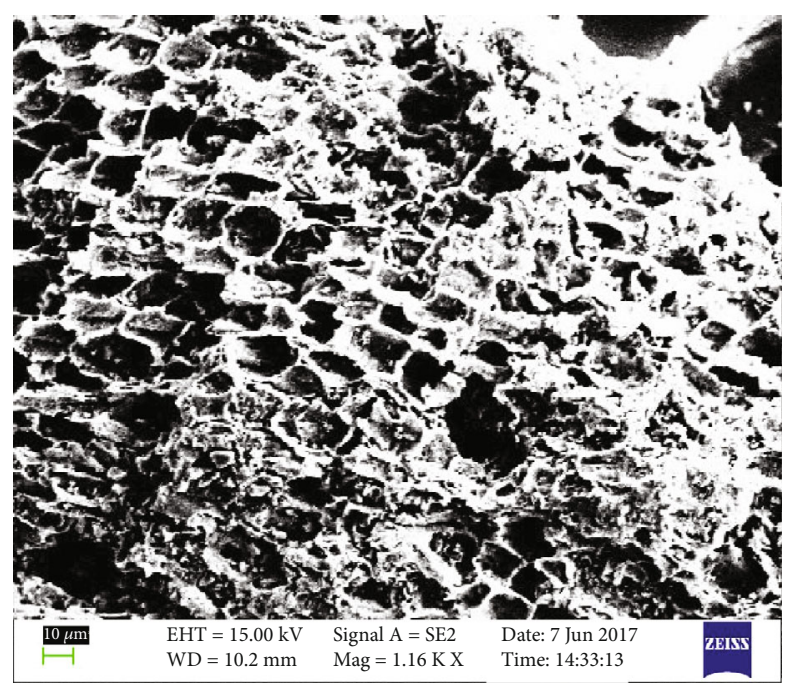

(c)

Figure 3: SEM micrograph of (a) HUAC, (b) BG4 loaded HUAC, and (c) AF loaded HUAC.

Figure 4(ii). The UV-vis spectrum of AF dye in Figure 4(ii) (a) has a large peak at $543 \mathrm{~nm}$. This peak is not found in the spectrum (b) that depicts the maximum adsorption of AF dye by HUAC.

4.2. Effect of $\mathrm{pH}$ on Dye Removal. The $\mathrm{pH}$ of the solution influences the surface behavior of the adsorbent and ionization characteristics of the adsorbate. From the experimental data, it is found that the removal efficiency of BG4 dye has increased with $\mathrm{pH}$ as shown in Figure 5. However, maximum adsorption of $79.76 \mathrm{mg} / \mathrm{g}$ of BG4 was observed at $\mathrm{pH} 10$ (97.94\%) which is comparatively better than the use of $\mathrm{HCl}$ pretreated clay and $\mathrm{MnFe}_{2} \mathrm{O}_{4}$ clay composite in the removal of methyl green that reported maximum adsorption of $44 \mathrm{mg} / \mathrm{g}$ at $\mathrm{pH} 8$ [19]. Low $\mathrm{pH}$ produces protonation on the HUAC surface creating a cationic environment which strongly repels the positive part of the dye [20]. However, as $\mathrm{pH}$ increases, the number of $\mathrm{OH}$ groups increases on the surface of HUAC that attracts the quaternary ammonium group of the dye by hydrogen bonds as shown by the mechanism in Figure 6. This results in high BG4 dye diffusion onto HUAC. Very low $\mathrm{pH}$ attributes to the instability of the dye. Unlike BG4, AF exhibits good adherence to HUAC at lower $\mathrm{pH}(76.7 \%$ removal at $\mathrm{pH} 4)$. This may be due to the fact that at lower $\mathrm{pH}$ the protonic clouds on the HUAC surface attract the sulphonic acid group of AF thus accounting for more adsorption as displayed in Figure 6 [21]. The plot shows a decrease in AF uptake beyond $\mathrm{pH}$ 4. This may be due to an increase in negative charge density at higher $\mathrm{pH}$ thus repelling the dye ions and decreasing the rate of adsorption.

4.3. Effect of Adsorbent Dose on Dye Removal. The addition of adsorbent to the aqueous solution of the dyes revealed that dye removal efficiency improved on increasing the doses of adsorbent. Figure 7 indicates the maximum removal of BG4 of about $97.94 \%$ for $0.1 \mathrm{~g}$ of HUAC dose and maximum removal of $\mathrm{AF}$ of $76.6 \%$ for $0.03 \mathrm{~g}$ of $\mathrm{HUAC}$ dose and becomes steady further. It may be due to the increase in 


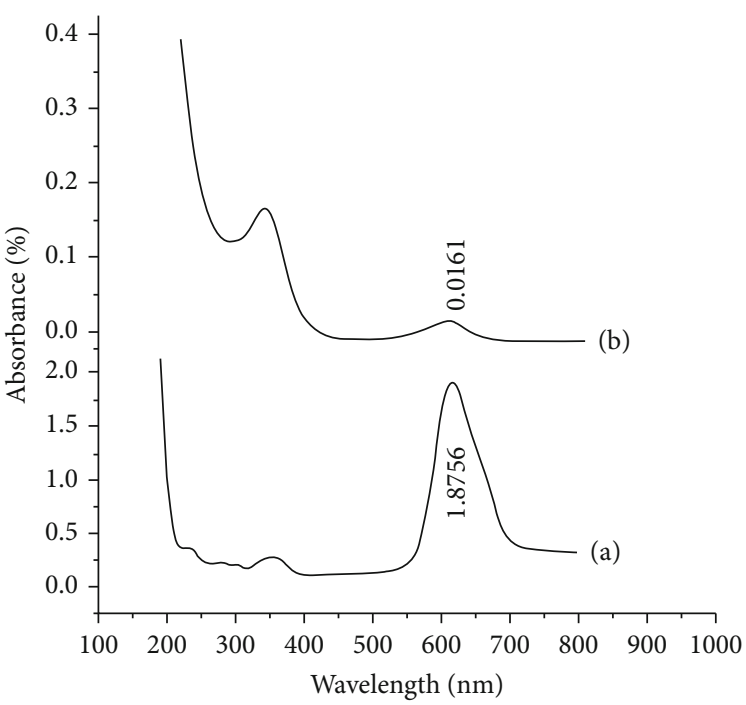

(a)

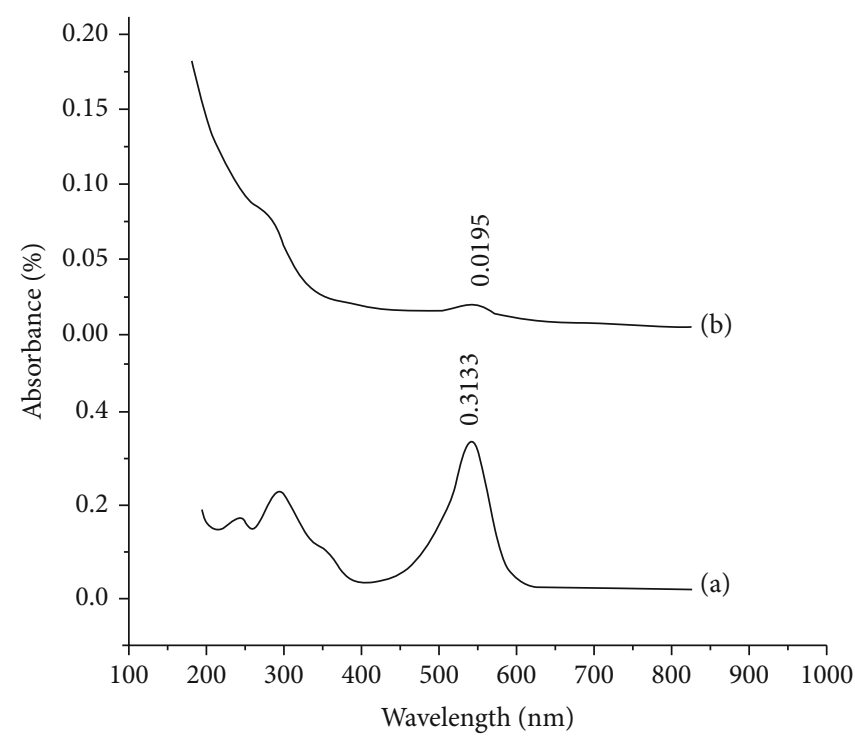

(b)

FIgURE 4: (i) UV-vis spectrum of BG4 dye and (ii) AF dye before and after adsorption.

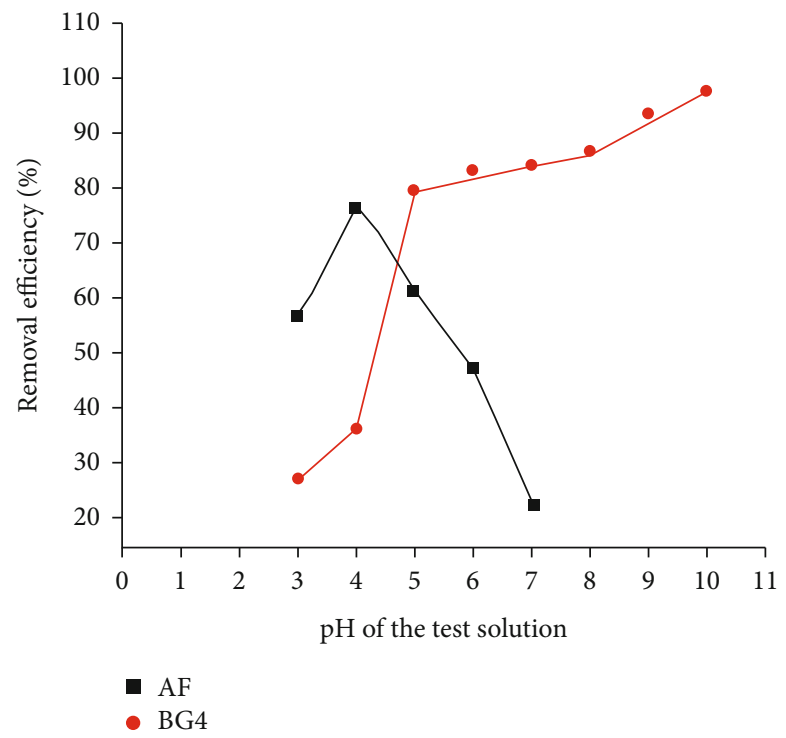

FIgURE 5: Effect of $\mathrm{pH}$ on the dye removal efficiency of HUAC.

surface area with more number of binding sites on HUAC for dye uptake with an increase in the adsorbent dose [22]. A steady-state was found beyond the saturation point due to an equilibrium established between dye molecules on the adsorbent and within the solution [4].

4.4. Effect of Initial Dye Concentration and Agitation Time. Figure 8 shows an increase in the amount of dye adsorbed with increase in initial concentration of aqueous BG4 upto $50 \mathrm{ppm}(79.76 \mathrm{mg} / \mathrm{g})$ and falls beyond. The adsorption of $\mathrm{AF}$ onto HUAC finds a gradual rise with increase in initial concentration of aqueous AF upto $100 \mathrm{ppm}(91.08 \mathrm{mg} / \mathrm{g})$. This depicts that there is a better interaction between dye ions and the binding sites of HUAC at lower dye concentration [23].
The influence of agitation time on the removal efficiency of the dyes was examined in the range of $30-120 \mathrm{~min}$. Figure 9 indicates an increase in removal efficiency of BG4 and AF with time. The plot shows $98 \%$ and $76.2 \%$ of BG4 and AF removal at 90 minutes and 120 minutes, respectively, that implies fast diffusion of the dye into the voids of the adsorbent. Diffusion continues with time of contact until equilibrium is reached between the dye concentration within the adsorbent and the solution beyond which there is no significant dye removal. This behavior may be due to the presence of exhausted sites in the adsorbent that repel the incoming ions [24].

4.5. Isotherm Studies. The study on adsorption isotherm is very important in describing the adsorption characteristics 

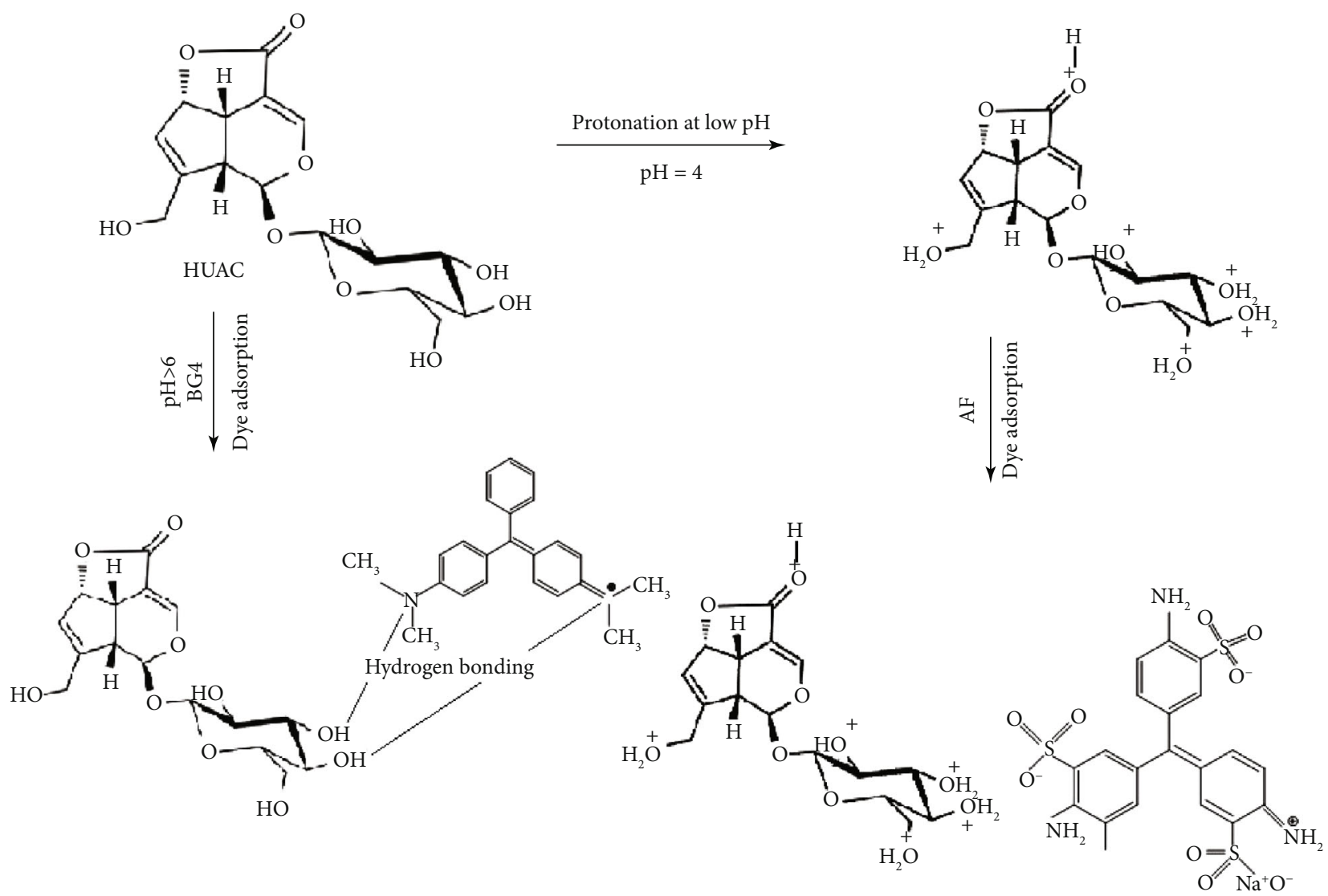

FIgURE 6: Proposed mechanism for adsorption of BG4 and AF dyes on HUAC.

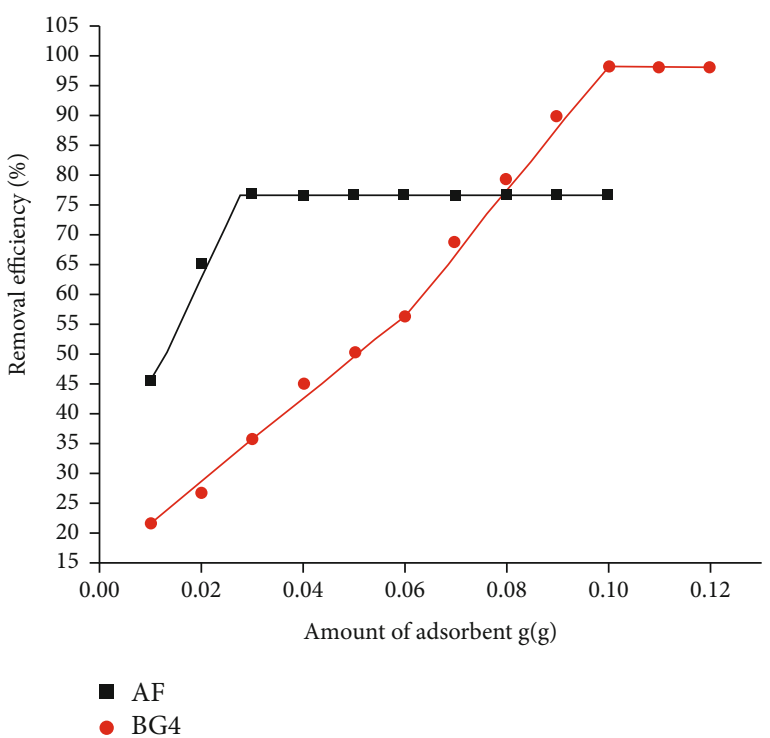

Figure 7: Effect of adsorbent dose on dye removal efficiency of HUAC.

for a solid-liquid adsorption system [25]. Figure 10 gives the Langmuir plot (Ce vs. Ce/qe) for BG4 and AF adsorption and isotherm constants $q_{m}$ and $K_{L}$ are from the slope and intercept, respectively. Langmuir isotherm assumes adsorption at homogeneous sites on the adsorbent thus forming a satu-

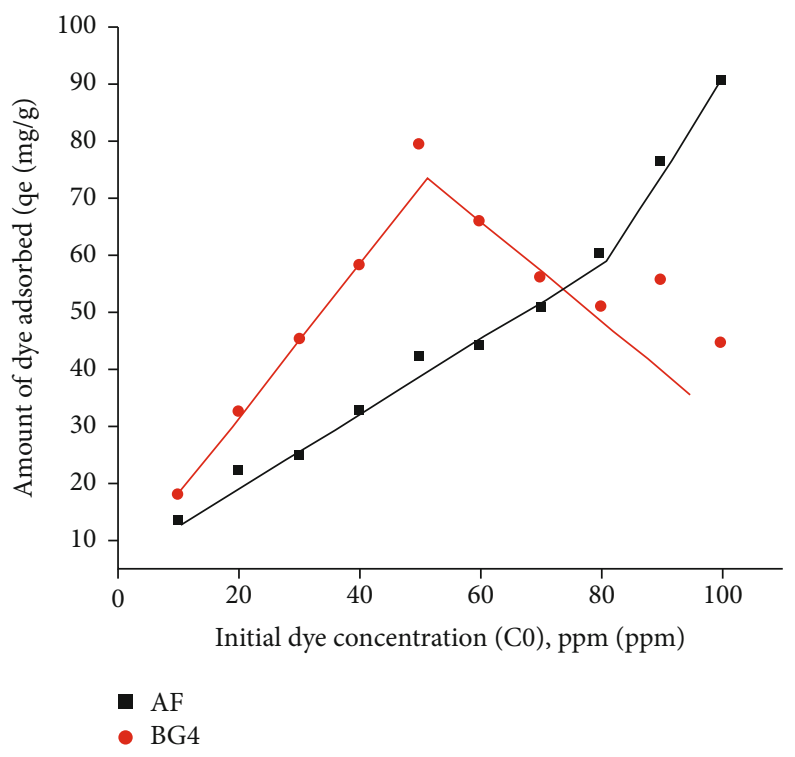

FIgURe 8: Effect of initial dye concentration on dye efficiency removal efficiency of HUMG.

rated monolayer of the dye inside the pores [26]. The dimensionless separation factor $R_{L}$ (if $0<R_{L}<1$ favourable, $R_{L}>1$ unfavorable, $R_{L}=0$ irreversible) for BG4 lies between 0 and 1 indicates favorability of the model [27] and monolayer 


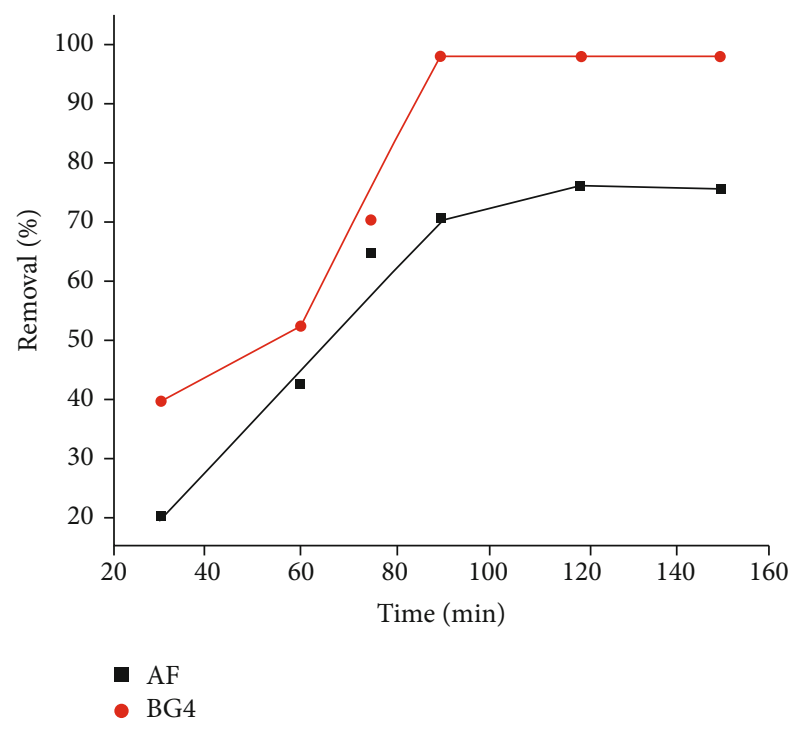

FIgURE 9: Effect of contact time on the dye removal of HUAC.

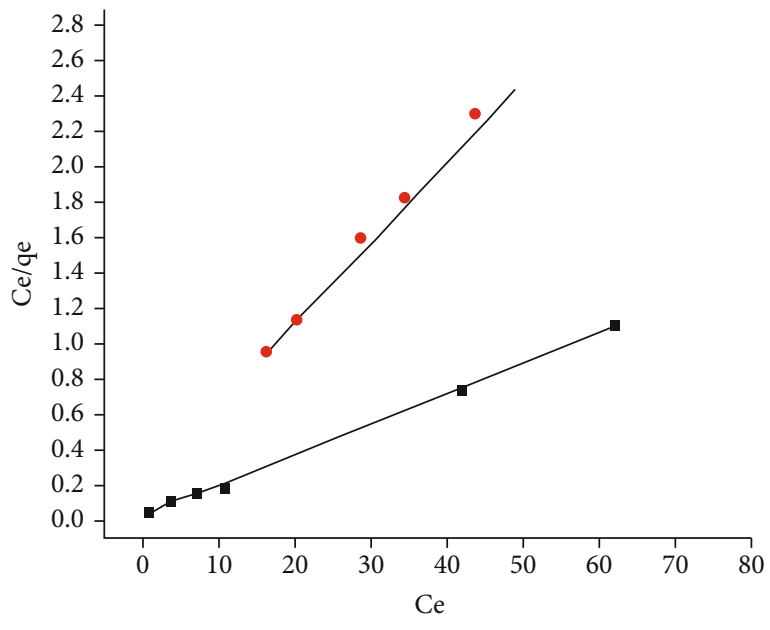

- BG4

- $\mathrm{AF}$

FIgUre 10: Langmuir plot of BG4 and AF adsorption onto HUAC.

adsorption of BG4 over a homogeneous HUAC surface with the maximum removal of $97.94 \%$. This shows the attainment of saturation point of the pores beyond which no further adsorption is possible on the same site [28]. This is also supported by fairly linear plot and high coefficient of determination, $R^{2}>0.985$ at all temperatures for BG4 adsorption thus confirmed a good fit of Langmuir isotherm. However, for AF adsorption, $R_{L} \geq 1$ implies unfavorable Langmuir interaction and the calculated coefficient, $R^{2}<0.89$.

Freundlich isotherm describes heterogeneity and multilayer adsorption process. Figure 11 shows the Freundlich plot $\left(\log q_{e}\right.$ vs. $\left.\log C_{e}\right)$ for adsorption of BG4 and AF dye on HUAC where the slope and intercept give the values of Freundlich constants $n$ and $K_{F}$, respectively. Freundlich constant $1 / n<1(1 / n=0.60-0.61)$ for AF dye proves the feasibility of multilayer adsorption of the dye on HUAC [29].

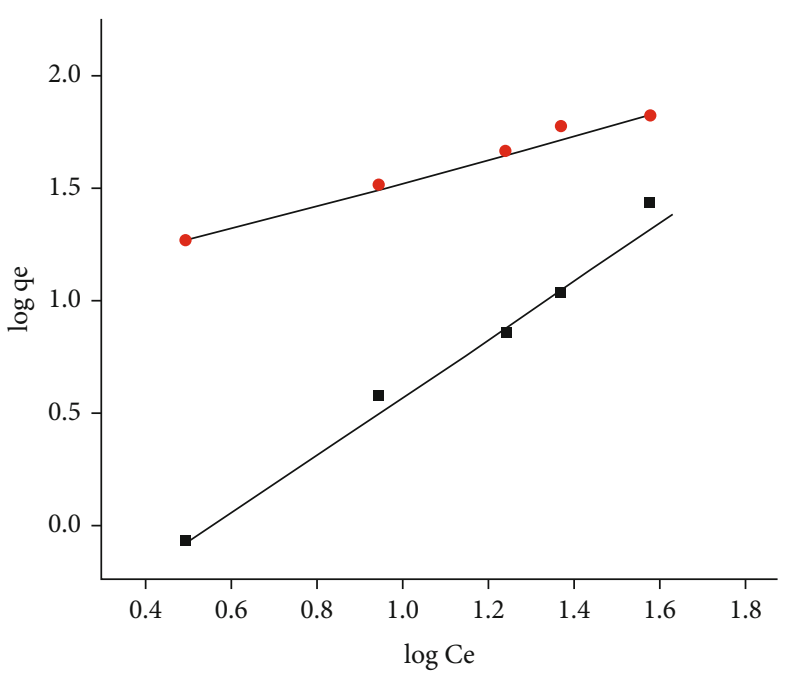

- BG4

- $\mathrm{AF}$

FIgURE 11: Freundlich plot of BG4 and AF adsorption onto HUAC.

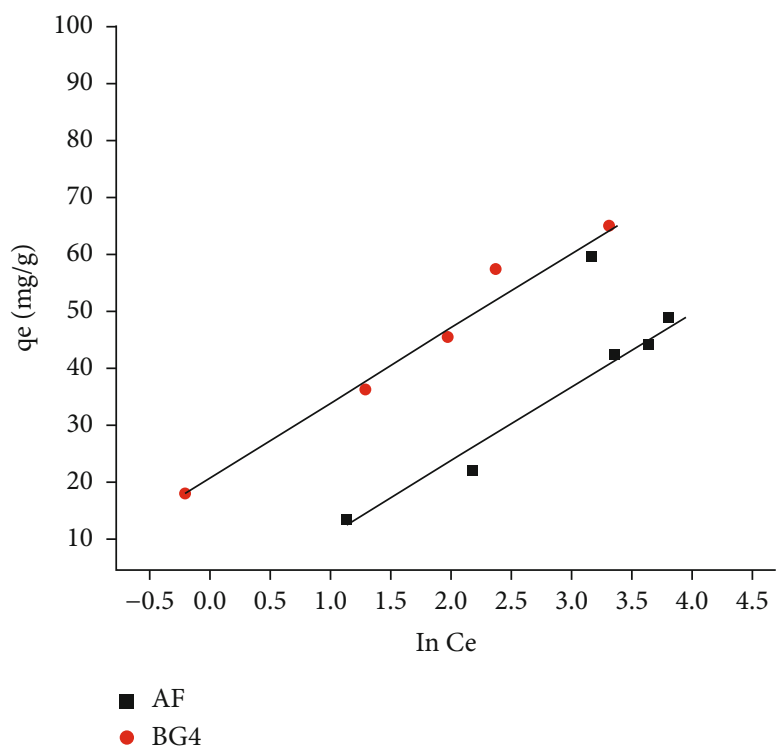

FIgURE 12: Temkin plot for adsorption of basic green 4 dye onto HUAC.

During multilayer adsorption of AF dye, the energy of interaction between the adsorbate and the adsorbent is strongest in the first layer and gradually decreases for the subsequent layers. This results in the maximum removal efficiency of $76.7 \%$ of AF dye by HUAC. The adsorption of AF dye on HUAC displays best fit in Freundlich plot $\left(R^{2}{ }_{\max }=0.9883\right)$ whereas adsorption of BG4 dye shows no linear correlation $\left(R_{\max }^{2}=0.9398\right)$ between the variables $C_{e}$ and $q_{e}$. Figure 12 shows the Temkin plot $\left(\ln C_{e}\right.$ vs. $\left.q_{e}\right)$ that did not exhibit fair correlation for BG4 adsorption, the plot for adsorption of AF dye shows a medium correlation, and the values of constants are listed in Table 3. 
TABLE 3: Adsorption isotherm parameters.

(a)

\begin{tabular}{|c|c|c|c|c|c|c|c|c|c|}
\hline \multicolumn{10}{|c|}{ Basic green 4} \\
\hline \multirow[b]{2}{*}{ Temp (K) } & \multicolumn{3}{|c|}{ Langmuir } & \multicolumn{3}{|c|}{ Freundlich } & \multicolumn{3}{|c|}{ Temkin } \\
\hline & $q_{m}(\mathrm{mg} / \mathrm{g})$ & $K_{L}$ & $R^{2}$ & $K_{F}$ & $1 / n$ & $R^{2}$ & $A_{T}$ & $b$ & $R^{2}$ \\
\hline 303 & 48.95 & 0.488 & 0.9852 & 26.9 & 0.207 & 0.7244 & 6.576 & 709.6 & 0.8838 \\
\hline 318 & 100 & 0.588 & 0.9973 & 30.20 & 0.279 & 0.8517 & 12.66 & 791.57 & 0.8592 \\
\hline 333 & 100 & 0.714 & 0.9945 & 35.48 & 0.287 & 0.9071 & 30.27 & 925.9 & 0.8560 \\
\hline 348 & 102.38 & 0.516 & 0.9978 & 36.3 & 0.304 & 0.9398 & 33.65 & 974.16 & 0.8590 \\
\hline
\end{tabular}

(b)

\begin{tabular}{lccccccccc}
\hline & & \multicolumn{3}{c}{ Acid fuchsin } & & \multicolumn{3}{c}{ Temkin } \\
Temp $(\mathrm{K})$ & $q_{m}(\mathrm{mg} / \mathrm{g})$ & $K_{L}$ & $R^{2}$ & $K_{F}$ & $1 / n$ & $R^{2}$ & $A_{T}$ & $b$ & $R^{2}$ \\
\hline 303 & 133.03 & 0.018 & 0.6814 & 5.834 & 0.602 & 0.9458 & 1.088 & 473.8 & 0.8456 \\
318 & 134.87 & 0.0208 & 0.7455 & 6.162 & 0.61 & 0.9619 & 1.054 & 495.4 & 0.8510 \\
333 & 132.83 & 0.0266 & 0.8509 & 7.298 & 0.60 & 0.9831 & 1.067 & 525.4 & 0.8640 \\
348 & 139.33 & 0.0332 & 0.8953 & 8.576 & 0.60 & 0.9883 & 1.238 & 555.0 & 0.8716 \\
\hline
\end{tabular}

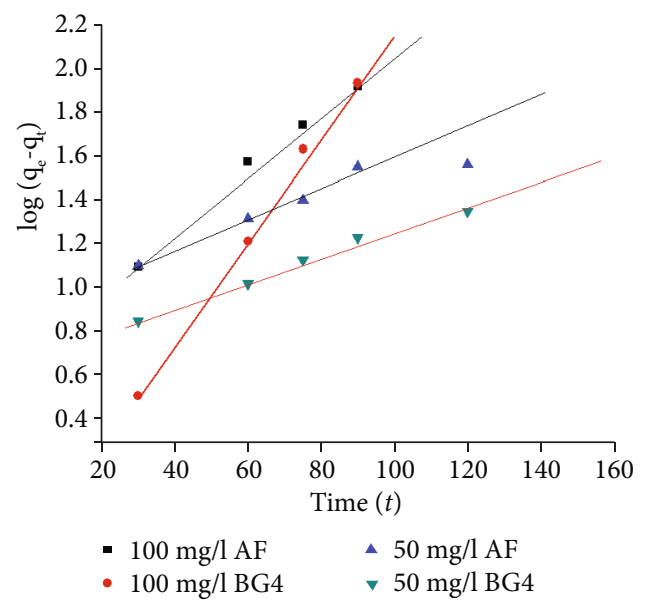

FIGURE 13: Pseudofirst order model of AF and BG4 adsorption onto HUAC.

4.6. Kinetic Studies. Kinetic models such as pseudofirst order, pseudosecond order, and intraparticle diffusion models were used to interpret the experimented data [13]. The plot $\left(\log \left(q_{e}-q_{t}\right)\right.$ vs. $\left.t\right)$ for linearized Lagergren pseudofirst order equation is given by Figure 13. The values of rate constant, $k 1$, were calculated from the slope and coefficient of determination, and $R^{2}$ is listed in Table 4 . The straight lines in the pseudofirst order plot for BG4 and AF dyes imply the feasibility of pseudofirst order kinetics. Further, the values of coefficient of determination, $R^{2}>0.9$, for BG4 and AF adsorption confirm the best fit [30]. However, pseudosecond order plot $\left(t / q_{t}\right.$ vs. $\left.t\right)$ shown in Figure 14 did not indicate a good compliance for all the concentrations of BG4 and AF dye adsorption and thus proves the nonproximity of the model against the examined data.

The intraparticle diffusion mechanism ascribes to the travelling of dye molecules from the bulk of the solution to the solid adsorbent. This mechanism can be understood from the plot $\left(q_{t}\right.$ vs. $\left.t^{1 / 2}\right)$ for BG4 and AF dye adsorption as displayed in Figure 15. The plot indicates a nonlinear regression for most of the concentrations of BG4 dye and skips away from the origin. This infers that intraparticle diffusion follows a monolayer film diffusion mechanism. In contrast to this, AF dye adsorption followed intraparticle pore diffusion mechanism onto HUAC. This fact is supported by high coefficient of determination values $(>0.99)$, and the plot lines pass through the origin confirming that intraparticle diffusion is the rate-limiting step [31].

4.7. Thermodynamic Studies. The values of $\Delta G^{0}, \Delta H^{0}$, and $\Delta S^{0}$ were calculated for the adsorption of BG4 and AF dyes on HUAC as listed in Table 5. $\Delta H^{0}$ and $\Delta S^{0}$ were obtained from the slope and intercept of the linear plot of $\ln K_{L}$ vs. $1 / T$ as shown in Figure 16. The maximum adsorption of 
TABle 4: Adsorption kinetic parameters.

\begin{tabular}{|c|c|c|c|c|c|c|c|c|}
\hline \multirow[b]{2}{*}{$C_{0}(\mathrm{mg} / \mathrm{l})$} & \multicolumn{3}{|c|}{ Pseudofirst order } & \multicolumn{3}{|c|}{ Pseudosecond order } & \multicolumn{2}{|c|}{$\begin{array}{c}\text { Intraparticle } \\
\text { diffusion }\end{array}$} \\
\hline & $q_{e}(\exp )$ & $q_{e}(\mathrm{cal})$ & $k_{1}$ & $R^{2}$ & $k_{2}$ & $R^{2}$ & $k_{i}$ & $R^{2}$ \\
\hline 50 (BG4) & 79.76 & 16.3 & 0.01 & 0.9986 & 0.0012 & 0.9032 & 1.81 & 0.9035 \\
\hline $50(\mathrm{AF})$ & 28.69 & 10.47 & 0.012 & 0.9500 & 0.0009 & 0.9322 & 9.63 & 0.9945 \\
\hline $100(\mathrm{BG} 4)$ & 44.92 & 10.82 & 0.031 & 0.9963 & 0.0005 & 0.9456 & 12.97 & 0.8867 \\
\hline $100(\mathrm{AF})$ & 45.54 & 13.49 & 0.016 & 0.9597 & 0.0003 & 0.9004 & 6.05 & 0.9926 \\
\hline
\end{tabular}

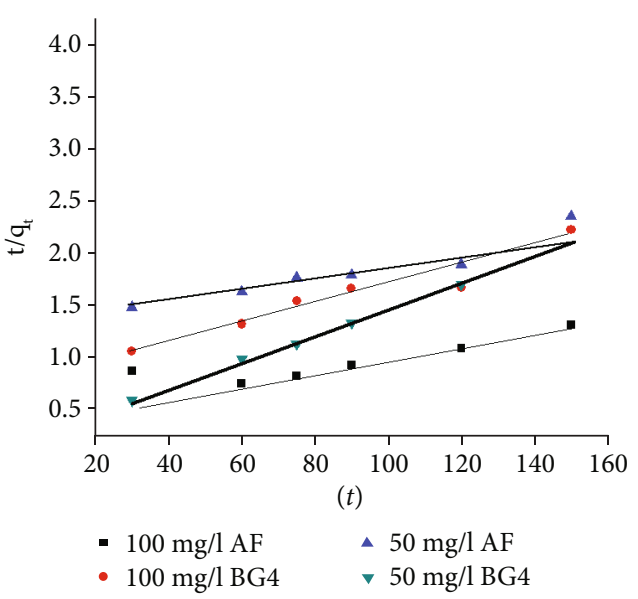

Figure 14: Pseudosecond order model for BG4 and AF adsorption onto HUAC.

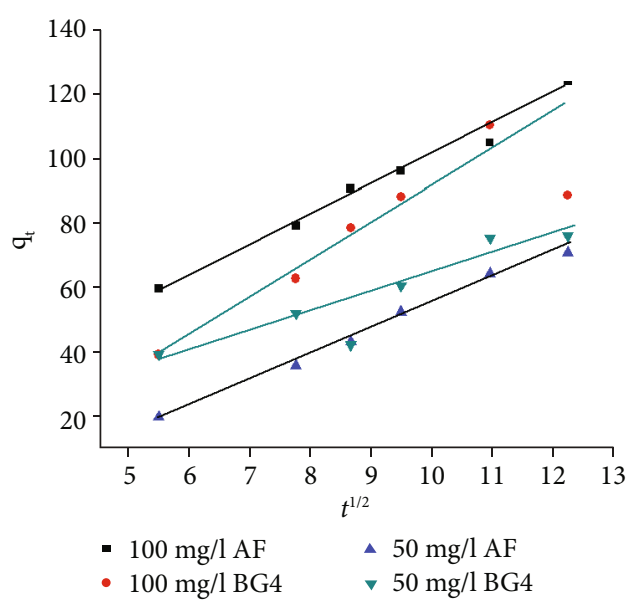

Figure 15: Intraparticle diffusion model for adsorption of basic green 4 dye onto HUAC.

BG4 and AF dyes from aqueous solutions on HUAC was achieved at room temperature $(303 \mathrm{~K})$. This may be due to the weakening of intermolecular forces in the dyes which is responsible for their adsorption [32]. As temperature increases, free energy change $\left(\Delta G^{0}\right)$ for the adsorption of BG4 and AF dyes possesses higher negative values and confirms that the reaction is exothermic and spontaneous. The negative values of $\Delta H^{0}$ for adsorption of BG4 and AF onto HUAC also prove the exothermic nature. The pos-
TABle 5: Thermodynamic parameters.

\begin{tabular}{ccccc}
\hline Dyes & Temperature (K) & $\begin{array}{c}\Delta G \\
\left(\mathrm{KJmol}^{-1}\right)\end{array}$ & $\begin{array}{c}\Delta H \\
\left(\mathrm{KJmol}^{-1}\right)\end{array}$ & $\begin{array}{c}\Delta S \\
\left(\mathrm{Jmol}^{-1} \mathrm{~K}^{-1}\right)\end{array}$ \\
\hline \multirow{4}{*}{ BG4 } & 303 & -5.290 & & \\
& 318 & -6.610 & -1.157 & 6.012 \\
& 333 & -7.198 & & \\
& 348 & -7.812 & & \\
AF & 303 & -0.995 & & 4.002 \\
& 318 & -1.583 & & \\
\hline
\end{tabular}

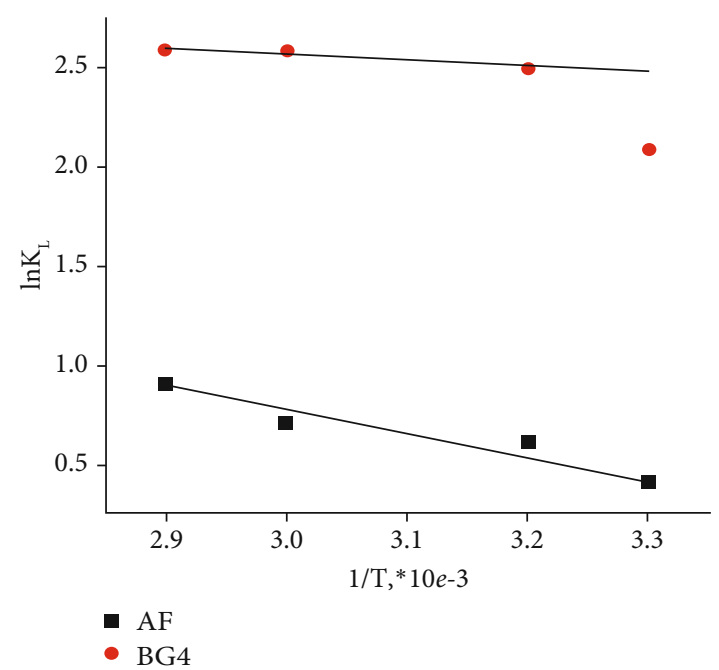

FIgURE 16: Van't Hoff plot model for BG4 and AF adsorption onto HUAC.

itive values of $\Delta S^{0}$ indicate increase in randomness at the carbon-dye interface during the adsorption of dyes onto HUAC. The decrease in standard free energy with increase in temperature implies the increase in the amount of dyes adsorbed at equilibrium.

4.8. Comparison with Other Adsorbents. Table 6 shows the comparison of the adsorption capacity of HUAC for BG4 and AF removal with a few other adsorbents. It may be noted that the amount of dye adsorbed is relatively more by HUAC than other adsorbents at similar conditions. Thus, it can be concluded that HUAC may be used as an efficient adsorbent. 
TABLE 6: Comparison of adsorption capacity of HUAC with other adsorbents.

\begin{tabular}{|c|c|c|c|c|c|}
\hline Adsorbent & $\mathrm{pH}$ & Concentration (mg/L) & Maximum adsorption capacity (mg/g) & Dye & References \\
\hline Rambutan seed & 8.0 & 100 & 73.43 & BG4 & Ahmad et al. [4] \\
\hline Spent tea leaves & 4.0 & 100 & 123.5 & BG4 & Akar et al. [5] \\
\hline Carob & 4.0 & 100 & 73.54 & BG4 & Saygili et al. [6] \\
\hline Pomelo peels & 8.0 & 100 & 178.43 & BG4 & Bello et al. [8] \\
\hline Hedyotis umbellate & 10.0 & 50 & 102.38 & BG4 & This work \\
\hline LTA-type zeolite (fly ash) & 5.4 & 50 & 40.64 & $\mathrm{AF}$ & $\mathrm{Xu}$ et al. [21] \\
\hline Zeolite 5A & 2.0 & 250 & 93.68 & $\mathrm{AF}$ & Ahmedzeki et al. [33] \\
\hline Laccase modified zeolite & 5.0 & 50 & 31 & $\mathrm{AF}$ & Kalkan et al. [34] \\
\hline Malted sorghum mash & 4.0 & 50 & 58.48 & $\mathrm{AF}$ & Oyelude et al. [11] \\
\hline Hedyotis umbellate & 4.0 & 100 & 133.03 & $\mathrm{AF}$ & This work \\
\hline
\end{tabular}

\section{Conclusion}

The waste biomaterial was derived from Hedyotis umbellate, and its potential was evaluated in the aspect of removing highly toxic water-soluble acid and basic dyes, BG4 and AF from the aqueous solution by batch mode. The sorption capacity in terms of $\mathrm{pH}$ of the solution, adsorbent dose, agitation time, initial dye concentration, and temperature was examined. The control parameters were optimized and fixed. The isotherm investigation on adsorption of BG4 dye on HUAC revealed best fit of Langmuir isotherm which indicated monolayer adsorption of BG4 dye, and the adsorption of AF dye proved best fit of Freundlich isotherm that indicated multilayer diffusion of AF dye on HUAC. The kinetic studies confirmed pseudofirst order mechanism for the adsorption of BG4 and AF dyes onto HUAC. The adsorption of AF dye is driven by intraparticle diffusion. Therefore, Hedyotis umbellate activated carbon can be used as a cost effective and an efficient adsorbent for the removal of toxic dyes such as BG4 and AF from aqueous solution.

\section{Data Availability}

All data are included in the article itself. There is no separate data sheet available.

\section{Conflicts of Interest}

The authors declare that they have no conflicts of interest.

\section{Supplementary Materials}

Supplementary material uploaded. (Supplementary Materials)

\section{References}

[1] M. Rajabi, B. Mirza, K. Mahanpoor et al., "Adsorption of malachite green from aqueous solution by carboxylate group functionalized multi-walled carbon nanotubes: determination of equilibrium and kinetics parameters," Journal of Industrial and Engineering Chemistry, vol. 34, pp. 130-138, 2016.

[2] M. Dutta and J. K. Basu, "Fixed-bed column study for the adsorptive removal of acid fuchsin using carbon-alumina composite pellet," International journal of Environmental Science and Technology, vol. 11, no. 1, pp. 87-96, 2014.

[3] Material Safety Data Sheet, Scholar Chemistry MSDS 296, p. 2, 2009.

[4] M. A. Ahmad, N. S. Afandi, K. A. Adegoke, and O. S. Bello, "Optimization and batch studies on adsorption of malachite green dye using rambutan seed activated carbon," Desalination and Water Treatment, vol. 57, no. 45, pp. 21487-21511, 2016.

[5] E. Akar, A. Altinisik, and Y. Seki, "Using of activated carbon produced from spent tea leaves for the removal of malachite green from aqueous solution," Ecological Engineering, vol. 52, pp. 19-27, 2013.

[6] H. Saygili and F. Guzel, "Uptake of anionic and cationic dyes by highly effective porous carbon adsorber based on industrial processing residues," Separation Science and Technology, vol. 53, no. 10, pp. 1465-1475, 2018.

[7] Ü. Geçgel, O. Üner, G. Gökara, and Y. Bayrak, “Adsorption of cationic dyes on activated carbon obtained from wasteElaeagnusstone," Adsorption Science and Technology, vol. 34, no. 910, pp. 512-525, 2016.

[8] O. S. Bello, M. A. Ahmad, and B. Semire, "Scavenging malachite green dye from aqueous solutions using pomelo (Citrus grandis) peels: kinetic, equilibrium and thermodynamic studies," Desalination and Water Treatment, vol. 56, no. 2, pp. 115, 2014.

[9] M. Ahiduzzaman and A. K. M. Sadrul Islam, "Preparation of porous bio-char and activated carbon from rice husk by leaching ash and chemical activation," Springerplus, vol. 5, no. 1, p. 1248, 2016.

[10] D. Li, J. Yan, Z. Liu, and Z. Liu, “Adsorption kinetic studies for removal of methylene blue using activated carbon prepared from sugar beet pulp," International journal of Environmental Science and Technology, vol. 13, no. 7, pp. 1815-1822, 2016.

[11] E. O. Oyelude, F. Frimpong, and D. Dawson, "Studies on the removal of basic fuchsin dye from aqueous solution by $\mathrm{HCl}$ treated sorghum mash," Journal of Materials and Environmental Science, vol. 6, no. 4, pp. 1126-1136, 2015.

[12] S. Vasanth, R. H. Gopal, S. Rekha, and V. Srinivasan, "The in vitro antibacterial activity ofHedyotis Umbellata," Indian Journal of Pharmaceutical Sciences, vol. 68, no. 2, pp. 236238, 2006.

[13] S. Madhavakrishnan, K. Manickavasagam, K. Rasappan, P. S. S. Shabudeen, R. Venkatesh, and S. Pattabhi, "Ricinus communis pericarp activated carbon used as an adsorbent for the 
removal of $\mathrm{Ni}(\mathrm{II})$ from aqueous solution," E-Journal of Chemistry, vol. 5, no. 4, pp. 761-769, 2008.

[14] A. S. Sartape, A. M. Mandhare, V. V. Jadhav, P. D. Raut, M. A. Anuse, and S. S. Kolekar, "Removal of malachite green dye from aqueous solution with adsorption technique using Limonia acidissima (wood apple) shell as low cost adsorbent," Arabian Journal of Chemistry, vol. 10, pp. S3229-S3238, 2014.

[15] S. Benyoucef and M. Amrani, "Retracted: adsorption of phosphate ions onto low cost Aleppo pine adsorbent," Desalination, vol. 275, no. 1-3, pp. 231-236, 2011.

[16] Spectroscopy Tables, Beauchamp.

[17] S. Chowdhury, S. Chakraborty, and P. Saha, "Biosorption of basic green 4 from aqueous solution by Ananas comosus (pineapple) leaf powder," Colloids and Surfaces B: Biointerfaces, vol. 84, no. 2, pp. 520-527, 2011.

[18] C.-Y. Cao, T. Zhang, and Q. Cong, "Adsorption of acid fuchsin onto the chitosan - montmorillonite composite," Marine Georesources and Geotechnology, vol. 35, no. 6, pp. 799-805, 2017.

[19] A. Ehsan, H. N. Bhatti, M. Iqbal, and S. Noreen, "Native, acidic pre-treated and composite clay efficiency for the adsorption of dicationic dye in aqueous medium," Water Science and Technology, vol. 75, no. 4, pp. 753-764, 2016.

[20] S. de Gisi, G. Lofrano, M. Grassi, and M. Notarnicola, "Characteristics and adsorption capacities of low-cost sorbents for wastewater treatment: a review," Sustainable Materials and Technologies, vol. 9, pp. 10-40, 2016.

[21] H. Y. Xu, L. C. Wu, T. N. Shi, W. C. Liu, and S. Y. Qi, “Adsorption of acid fuchsin onto LTA-type zeolite derived from fly ash," SCIENCE CHINA Technological Sciences, vol. 57, no. 6, pp. 1127-1134, 2014.

[22] A. Mokhtar, S. Abdelkrim, A. Djelad et al., "Adsorption behavior of cationic and anionic dyes on magadiite-chitosan composite beads," Carbohydrate Polymers, vol. 229, p. 115399, 2020.

[23] K. G. Bhattacharyya and A. Sarma, "Adsorption characteristics of the dye, Brilliant Green, on Neem leaf powder," Dyes and Pigments, vol. 57, no. 3, pp. 211-222, 2003.

[24] N. Tahir, H. N. Bhatti, M. Iqbal, and S. Noreen, "Biopolymers composites with peanut hull waste biomass and application for crystal violet adsorption," International Journal of Biological Macromolecules, vol. 94, Part A, pp. 210-220, 2017.

[25] A. Djelad, A. Mokhtar, A. Khelifa, A. Bengueddach, and M. Sassi, "Alginate-whey an effective and green adsorbent for crystal violet removal: kinetic, thermodynamic and mechanism studies," International Journal of Biological Macromolecules, vol. 139, pp. 944-954, 2019.

[26] M. Belhadri, A. Mokhtar, S. Meziani, F. Belkhadem, M. Sassi, and A. Bengueddach, "Novel low-cost adsorbent based on economically modified bentonite for lead(II) removal from aqueous solutions," Arabian Journal of Geosciences, vol. 12, no. 3, p. $88,2019$.

[27] M. B. Desta, "Batch sorption experiments: Langmuir and Freundlich isotherm studies for the adsorption of textile metal ions onto teff straw (Eragrostis tef) agricultural waste," Journal of Thermodynamics, vol. 2013, Article ID 375830, 6 pages, 2013.
[28] S. Shoukat, H. N. Bhatti, M. Iqbal, and S. Noreen, "Mango stone biocomposite preparation and application for crystal violet adsorption: a mechanistic study," Microporous and Mesoporous Materials, vol. 239, pp. 180-189, 2017.

[29] B. H. Hameed, "Removal of cationic dye from aqueous solution using jackfruit peel as non- conventional low-cost adsorbent," Journal of Hazardous Materials, vol. 162, no. 1, pp. 344-350, 2009.

[30] N. Bouchikhi, M. Adjdir, K. C. Bendeddouche et al., "Enhancement of adsorption capacity of low cost mesoporous MCM-41 and their antibacterial and antifungal activities," Materials Research Express, vol. 6, no. 12, p. 1250j7, 2019.

[31] C. H. Chakrapani, C. S. Babu, K. N. K. Vani, and K. S. Rao, "Adsorption kinetics for the removal of fluoride from aqueous solution by activated carbon adsorbents derived from the peels of selected citrus fruits," E-Journal of Chemistry, vol. 7, Supplement 1, pp. S419-S427, 2010.

[32] S. Noreen, H. N. Bhatti, M. Zuber, M. Zahid, and M. Asgher, "Removal of actacid orange-RL dye using biocomposites: modeling studies," Polish Journal of Environmental Studies, vol. 26, no. 5, pp. 2125-2134, 2017.

[33] N. S. Ahmedzeki and A. Kamil, "Statistical analysis of the removal of acid fuchsin dye using zeolite 5A," Iraqi Journal of Chemical and Petroleum Engineering, vol. 18, no. 2, pp. 41-55, 2017.

[34] E. Kalkan, H. Nadaroglu, N. Celebi, H. Celik, and E. Tasgin, "Experimental study to remediate acid fuchsin dye using laccase-modified zeolite from aqueous solutions," Polish Journal of Environmental Studies, vol. 24, no. 1, pp. 115-124, 2015. 